

\author{
INTERNATIONAL JOURNAL OF RESEARCH - \\ GRANTHAALAYAH \\ A knowledge Repository
}

Social

\title{
ACTIVITY THEORY IS AN EFFECTIVE FRAMEWORK ON QUALITATIVE DATA ANALYSIS IN SOCIAL SCIENCES STUDIES
}

\author{
Dr Senevirathna Bandara ${ }^{* 1}$ \\ ${ }^{* 1}$ Senior Lecturer, Department of Humanities, Faculty of Social Sciences, Rajarata University of \\ Sri Lanka, Mihintale
}

\begin{abstract}
Qualitative and quantitative are main research approaches in research disciplines, in quantitative research methods, the data analysis process is mostly systematic, therefor numerical quantitative data analysis is easy rather than qualitative data analysing in qualitative research studies. Under such a situation qualitative researcher have to use different types of data analysing methods in their data analysing process and this data analysing process also complicated. Grounded Theory and Activity theory are common and easy theories which could be used in qualitative data analysing process. This research paper describes Activity theory (AT) and its advantages in qualitative data analysing procedure and content analysis method was used to collect information (data) for this study. Deferent types of documents were used to analyse the content of Activity Theory (AT), findings and discussing were based on collected information of AT content.
\end{abstract}

Keywords: Qualitative and Quantitative Research Approaches; Activity Theory; Grounded Theory; Content Analysis; Mediation; Subject-Object-Outcome; Division of Labour; Community; Tool; Rules.

Cite This Article: Dr Senevirathna Bandara. (2018). "ACTIVITY THEORY IS AN EFFECTIVE FRAMEWORK ON QUALITATIVE DATA ANALYSIS IN SOCIAL SCIENCES STUDIES." International Journal of Research - Granthaalayah, 6(7), 85-95. https://doi.org/10.29121/granthaalayah.v6.i7.2018.1287.

\section{Introduction}

Qualitative data analysis is a difficult issue and complex multidimensional subject for researchers, therefore researchers use different methods in their studies. Some researchers apply various theories or framework on qualitative data analysing process, grounded theory, activity theory are examples for some of theories. Activity theory is a more powerful tool for qualitative data analysis especially in Social Sciences and Education researches, so that nowadays this Activity theory is used in all over the World among qualitative researchers. This review paper articulates the history of Activity theory (AT) and the advantages, applications in Social, cultural, historical field in qualitative inquiries. Activity theory (AT) is a framework or descriptive tool (Nardi, 1996a). The Activity theory (AT) analyses is concluded with the ecology metaphor of policy analyses and it 
will provide comprehensive insights on the policy front. Engeström (2001) explains the contradiction of this context as contradictions that constitute a key concept or principle in AT. The contradictions are referred to as dilemma, disturbances, disco ordinations, problematic situations, conflicts, etc. The beginning of this paper focuses on explaining the cultural-historical framework of Activity Theory (AT).

\section{Review of Literature}

Literature reviewed showed some researches which successfully applied AT as a theoretical framework. Riverin (2006) used the AT framework for his PhD study in Deakin University, Australia. This research focused on investigating Effects of Online Professional Development on the Integration of Technology in Schools. Riverin (2006) study's research question was, "What effect does involvement in The Education Network of Ontario have on classroom practice and on the use of information technology in particular?" The methodology of this study was the case study method. The next study is 'The role of practical activities in primary school science'. This was conducted by Clark (2006) using the AT framework. The study focused on education in the primary school classroom in Australia. The research question for this study was. "What roles can practical activities play in primary school science?" In this study the case study method was used and four cases were investigated. Each case was described in depth, data presented and summarised. At the end of each case the data were analysed using the AT framework. The third study was conducted in Botswana, by Boitshwarelo (2007) for his PhD study in Deakin University, Melbourne, Australia. It aimed to investigate the possibilities, issues and challenges involved in ICT implementation for teacher professional development secondary schools in Botswana. This study included three sub-research questions: The main activity in this study was the training of inservice biology teachers in order for them to acquire knowledge and skills for improved teaching practice. The subject of the activity was biology teachers who participated in in-service workshops. The object was teacher-acquired knowledge and skills on 'the teaching of process skills in biology'. The outcome was better teaching practice and face-to face training the tool. The rules were government policies, school regulation and norms, in-service guidance and norms. School, ministry and organisers of in-service were the community. The rule of this activity was government- or ministry-provided facilities and funds, training and resources.

\section{Materials and Methods}

Methodology of this review is Content Analysis in qualitative research approach, in a content analysis method researcher analyse classifies textual materials, historical documents, newspaper stories, political speeches, open-ended interviews, diplomatic massages, psychological diaries, official publications ect. (Weber, 1990). For this paper the content of Activity theory was based on books, journals, conferences papers from the online libraries database of different Universities, science direct, Taylor \& Francis, and various other relevant sources. Objective of the research is; understand the important of Activity Theory in qualitative data analysing in Social Sciences studies and additionally this study focusses on articulate the historical cultural AT. 


\section{Results and Discussions}

According to the collected data through the content analysing of the AT, this section provides deep awareness about the AT, component of the AT and advantages of the AT.

\section{Introduction of Activity Theory}

Boitshawarelo (2007) believes AT is a powerful and clarifying tool for understanding complex learning situations. AT was introduced by L.S. Vygotsky, A.N. Leont'ev and A.R. Luria, Russian psychologists, in the 1920s and 1930s. Further, AT explains the relationship between the human agent and the objects of environment. The relationship is mediated by cultural means, tools and signs (Ryder, 2008), while, Waite (2005) believes that AT is a high level motivation concept which describes what the individual or group is trying to accomplish and typically indicates what outcomes they are working towards.

The concepts of AT have given great impact in specific fields of inquiry, such as learning and teaching. In addition, AT has been developed significantly in the areas of psychology, learning, cognition and child development in the post-World War II decades. The theoretical view and practical application of AT is currently developed by researchers in various parts of the world. Further, several researchers have discussed the relationship between AT and cultural psychology, as well as the implications and potential of AT and its accessibility in the multiple fields of research and practice. Currently AT contributes to the ongoing multidisciplinary cultural practice and practice-bound cognition. In addition, AT should not be regarded as a narrowly psychological theory because today it has become a broader approach that takes a new perspective, and develops novel conceptual tools for tracking many of the theoretical and methodological fields in Social Science. Even though AT has originated in Soviet Russia, today it is transcending its concepts globally into multidisciplinary societies (EngestrÖm \& Miettinen, 1999; Nardi, 1996b).

"Activity is in principle, open and universal. It should be taken as the form of historical and cultural creativity. The formation of human activity is also the beginning of personalise" (Davydov, 1999, p. 39). In addition, Jonassen and Murphy (1999, p. 61) distinguish the importance of AT as, “... a socio-cultural, socio-historical lens through which designers can analyse human activity systems. It focuses on the interaction of human activity and consciousness with its relevant environmental context". AT is a framework or descriptive tool (Nardi, 1996a) and it provides comprehensive insights on the policy front. Ryder (2008, p. 2) defines an activity as "the engagement of a subject towards a certain goal or objective". If the nature of an activity is unmediated, it is typically an activity which involves direct action between the subject and object. Furthermore Dennis, Frezzo et al $(2009$, p. 1) explain the application of AT as, "“...effective use for learning and for assessing requires a conceptual framework for the knowledge, skills and ways of thinking that are meant to be developed. It also requires physical and conceptual tools for students to interact which simulate systems, peers and instructors; for students to create simulation tasks".

\section{Definitions and principles of Activity Theory}

Definitions and principles of Activity Theory which are relevant to this study are defined in this section. The components of the AT are briefly defined as follows:

- The subject of an activity system is the individual or group whose viewpoint is adopted. 
- Object-refers to the 'raw material' or 'problem space' at which the activity is directed and which is modelled or transformed into outcomes with the help of physical and symbolic, external and internal tools and it precedes and motivates activity.

- The Tools-mediate the relationship between subject and object of the activity (Clark, 2006). They can be external, material (e.g. a textbook, a computer) or internal, symbolic (e.g. language). Tools take part in the transformation of the object into an outcome, which can be desired or unexpected. They can enable or constrain the activity.

- Community refers to the participants of an activity system, who share the same object.

- The division of labour involves the division of tasks and roles among members of the community and the divisions of power and status.

- Rules are explicit and implicit norms that regulate actions and interactions within the system (Murphy \& Rodriguez-Manzanares, 2008, p. 2).

In addition, Murphy \& Rodriguez-Manzanares (2008, pp. 2-3) summarises five principles of AT and these are formulated by Engeström (2001):

- The main unit of analysis in AT is the activity system.

- Multi-voiced nests refers to multiple perspectives, interests, and traditions, which can be a source of trouble and of transformation in the system, as members of an activity system "carry their own diverse histories" and the system itself "carries multiple layers and strands of history engraved in its artefacts, rules and conventions".

- The principle of historicity argues that the history of activity systems helps to understand their problems as well as their potentials because "parts of the older phases of activity often stay embedded in them as they develop" (Kutti, 1996).

- Contradictions can result in tensions, but also transformation in activity systems. In the context of education, for example, a contradiction in teachers' practice might occur when a new technology is introduced into their activity system and clashes with an old element.

- Expansive learning relates to the possibility of expansive transformation in activity systems through re-conceptualisation of the object and the motive of activity".

\section{Mediation}

The basic concept of the AT is the notion of mediation by tools (artefacts) (Nardi, 1996a). Riverin (2006) used a simple figure to view the mediated activity between stimulus, signs and response.
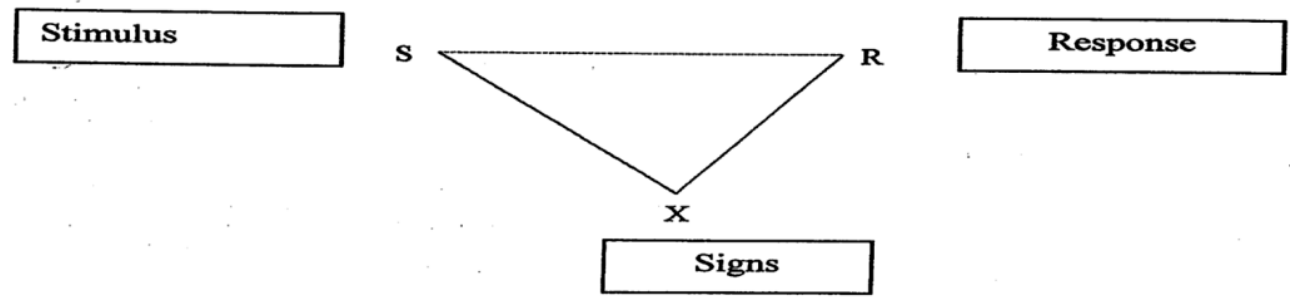

(Riverin, 2006)

Figure 1: The structure of the mediated activity

This mediated activity with the human environment formed the basis of Vygotskey's belief that humans constructed understanding as they interacted with their environment through signs and language (Riverin, 2006). This tool mediation is externally oriented and it leads to change in object. 
This section describes the mediation of basic subject-object-outcome activity. This activity is defined by Dennis, Frezzo et al (2009) as the cognition transferred (distributed) process.

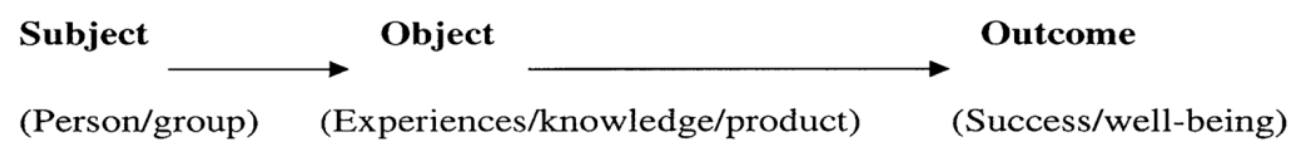

Figure 2: Basic subject-object-outcome activity

As Ryder points out, "In most human contexts, our activities are mediated through the use of culturally established instruments" (Ryder, 2008, p. 2). In addition Dennis, Frezzo et al (2009, p. 9) pointed out that, "Mediation by tools and singes is not merely a psychological idea. It is an idea that breaks down the Cartesian walls that isolate the individual mind from the culture and the society". The figure 03 below shows basic activity is mediated by tools (artefacts).

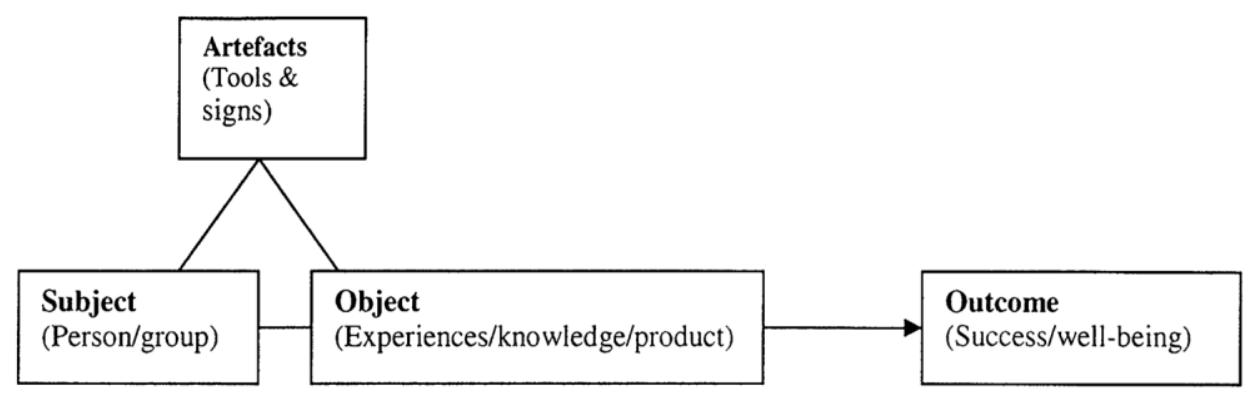

Figure 3: Subject-object mediation by tools

Some examples for Tools are: policy documents, samples, recipes, facilities, languages, established procedures, etc. As mediated by the tools the community also mediate the same activity. Figure 04 shows the basic activity is mediated by tools and community.



Figure 4: The basic activity is mediated by tools and community

In an activity, a human agent is the subject who is motivated towards the object, which is the solution of a problem or purpose. This process is mediated by tools (artefacts) in collaboration with others (community). Further, the structure of this activity system is constrained by cultural factors consisting social conventions (rules). In addition, social strata are represented by the 
division of labour (division of efforts or roles) within the context (Murphy \& RodriguezManzanares, 2008; Ryder, 2008; Waite, 2005; Williams et al., 2007). The following figure depicts the basic meditational triangle of the AT. It is described by Dennis, Frezzo et al (2009, p. 9) as, "Where the subject has two routes to act on object, a direct phylogenetic route and a second, indirect, artefact mediated, cultural route, from this basic triangle their explanation takes two directions. First, the intrinsic bidirectional and codetermination of the legs of the triangle are emphasised, for example, the subject acts on the object, but an image of the object is part of what determines the subject. Second, the dynamic nature of the activity triangle in time is also emphasised: the mutually constitutive, subject-mediator-object relations described by the triangle, far from being a static structure, often lead to a new subject, or more precisely, a new condition of the subject, at a later time". The figure 05 below shows the Engeström-introduced triangle of AT.

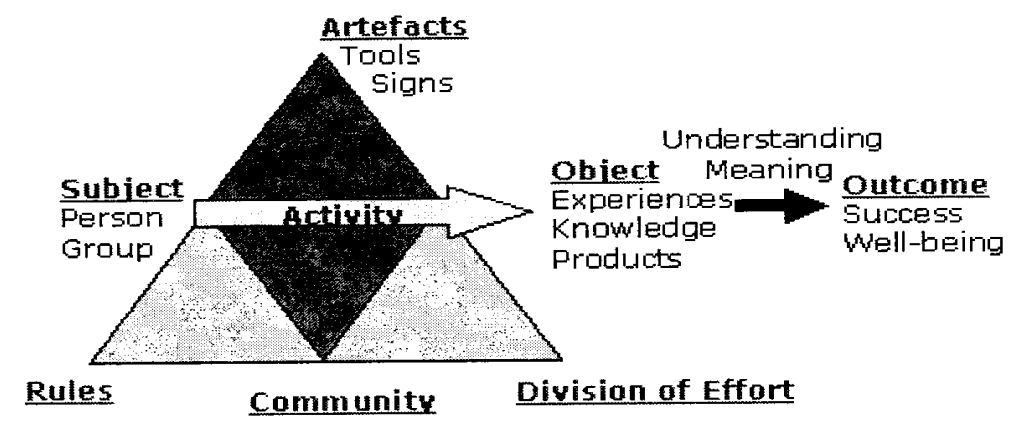

Figure 5: Engeström's classic model of Activity Theory: (University of Tasmania, 2008)

This model shows the relationship between the subject or individuals, the object and the community and the use of rules, tools and division of effort (roles) in the transformation of the object into the outcomes (University of Tasmania, 2008). Below figure 06 shows the interactions among components of the activity system of Engeström's model.

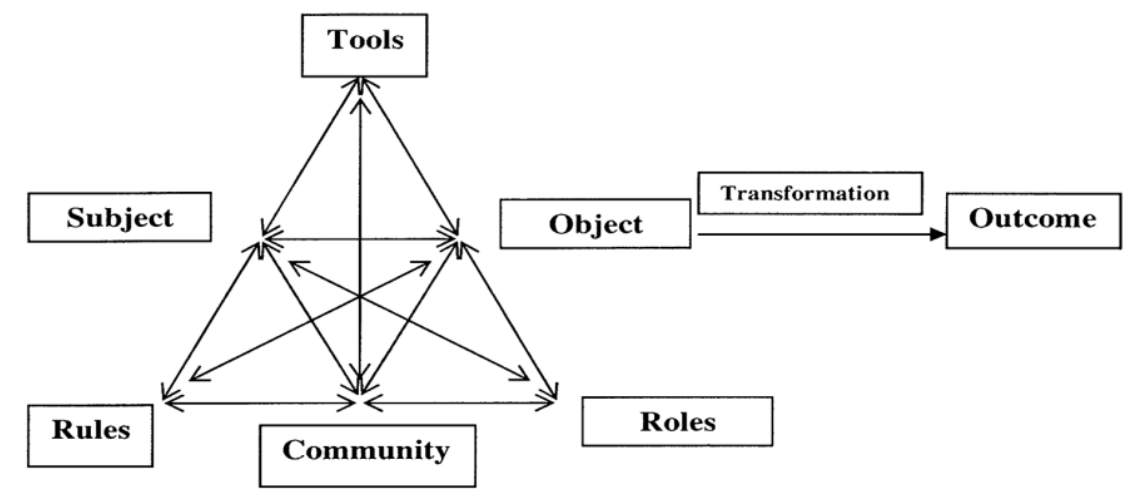

Figure 6: Interactions and integrations of the activity system: (Murphy and RodriguezManzanares, 2008)

Figure 06 depicts the typical activity system model (Engeström's classic model of AT or the basic meditational triangle of AT). The model of the typical structure of the activity system was formulated by Engeström (1987) and it consists of the interacting components (according to Clark (2006) 'nodes') of subject, object, tools (instruments or artefacts), division of labour, community, rules and outcome. 


\section{Assumptions of AT}

There are some assumptions which operate the activity theory. The assumptions are described in the following sub-sections.

\section{Unity of Consciousness}

One of the most significant fundamental assumptions of AT is that, "activity is the human integrations with the objective world and the conscious activities. That is a part of those interactions. Rather than learning before acting, as traditional theories prescribe, AT believes a theory that the human mind emerges and exists as a special component of interactions with the environment, so activity (sensory, mental, and physical) is a precursor to learning" (Jonassen \& Murphy, 1999, p. 64). Based on the activity system, the learner (subject) is the central, driving character of the activity. The AT views the mind and body (mental and physical) are interacting, and they are coexisting and mutually supportive. There is also a reciprocal regulatory feedback between knowledge and activity. Similarly, the traditional theories of learning believe in mindbody dualism with respect to the mind and external behaviour, but this separation is rejected by the AT. In this situation, AT explains that individuals cannot fully understand phenomena without acting on it (Jonassen \& Murphy, 1999; Boitshwarelo, 2007; Bandara, 2010).

\section{Intentionality}

The second assumption is that human and animals interact with their environment to better understand the environment and the world. These interactions enable fulfilling some goals and AT focuses on the purposeful actions that are realised through conscious intentions. These intentions are directed at the object of activity with the motive being to transform those objects into outcomes ((Jonassen \& Murphy, 1999; Boitshwarelo, 2007). Application in the teachinglearning process of the concept of intentionality is articulated by Riverin (2006). The highest cognitive development in a child was the ability to internalise an object as an abstract concept. He defines the development stage of a child as the stage at which the child can perform tasks alone, but that true teaching involved what he referred to as the 'Zone of Proximal Development' (ZPD). Teachers, either adults or capable peers, were needed in the ZPD of a child as assistants who help the child tap a development stage while encouraging growth to maturation. Therefore, teaching should consider, "assisting performance through a child's ZPD and focus on dialogs and discussion to hone higher cognitive skills" (Riverin, 2006, p. 18).

Further, AT believes that these interactions emerge from contradictions that individuals perceive as they interact with their environment. These intentions are directed to the objects of the activity to achieve the outcomes. This assumption is considered as the object-orientedness (Jonassen \& Murphy, 1999). Drawing on an activity theoretic formation of the object-oriented nature of the human activity forms the inner contradiction in cognitive theories that presuppose learning as intentional. In a learning situation, object is precisely outside of the inner. Further, Rothe (2000) believes that intentional does not exist as such as always has on object-intention is transitive, binding subject and object into an irreducible unite. Rothe (2000) pointed out that activity actions are oriented toward (collective) motives and individual goals and, he mentions these are intentional, though at different organisational levels. Further, intentional too is central to phenomenological perspective on perception generally and on learning. 


\section{Tools that mediate}

The tool (artefacts) always involves in the activity. These artefacts may be instruments, signs, procedures, machines, methods, laws and focus of work organisation (Nardi, 1996a; Waite, 2005). Further, "Tools are changed by the ways in which they have been used. In other words, tools are a reflection of their historical development - they change the process and are changed by the process" (Jonassen \& Murphy, 1999, p. 67). The tools that mediate are fundamental assumptions of the AT. In addition, the human experiences are shaped by the tools and signs systems, which they were used.

\section{Historical-cultural Dimension}

This assumption is focused on the historical-culture of human activities, and according to Jonassen and Murphy (1999) activity is a historically and culturally developed phenomenon. Further, activities evolve over time within a culture. “... an activity theory, the perspective, the process of instructional design or any activity can only be understood by analysing its historical development" (Jonassen \& Murphy, 1999, p. 66).

\section{Contradictions}

Contradictions are referred to as characteristics of the activity system and these constitute a key concept or principle in AT (EngestrÖm, 2001). Further, Murphy and Rodrignez-Manzanares (2008) explain the contradictions that constitute a key concept or principle in AT and the contradictions are referred to as dilemma, disturbances, disco-ordinations, problematic situations, conflicts etc. Contradictions are not simply conflicts or problems, although these are historically accumulating structural tensions within and between activity systems. The abovementioned contradictions are mostly internal, but sometimes they may be external to the system. The neighbouring systems can also be affected by the components of the activity system and these are called nested activities (see figure 08). Further, Engeström (2001) explains that contradictions (tensions) generate disturbances and conflicts, but also innovative attempts to change the activity. The activity system is constantly working through contradictions. Further, the notion of contradictions is the driving force of change and development in the activity system. Contradictions are developmentally significant and exist in the form of resistance to achieving the goals of the intended activity and an emerging dilemmas, disturbances and disco-ordinations. Lim and Hang (2003) mentioned two types of contradictions, first is primary inner contradictions, and these are appearing in each component of the activity system. The second is secondary inner contradictions and these can be seen among components of the activity system and other activity systems. For these primary and secondary contradictions Lim and Hang (2003) provide examples which are relevant to ICT education. They conducted a research in Singapore schools and the findings are discussed in a research paper. These findings provide examples for two types of contradictions:

"... a primary contradiction exist when a teacher, who has to effectively manage the class so as to achieve the intended object of facilitating the construction of students' knowledge, become overtaken with classroom management as the object because behaviours are difficult to manage. When ICT is introduced into the lesson, this primary contradiction may worsen because teachers have to manage more resources and possibly, monitor students more closely as leaner control increases. There is a constant latent tension between the intended object of engaging students in higher order thinking and the object of managing the class" Lim and Hang (2003, p. 53). 
Further they explain an example for secondary inner contradictions as: "...secondary inner contradictions may arise when there is a conflict between different processes in the activity system, for example, the role assigned to different members of the community in the traditional classroom may conflict with those required in ICT-mediated activities. When ICT tools such as computer simulations are introduced, which requires actions of inquiry and exploration from students, a secondary contradiction may appear between tools and DOL (Division of Labour) if the DOL is still very much teachers imparting knowledge and students receiving knowledge" (p. 53). The figure below shows the secondary inner contradictions of the activity system.



Figure 07: Secondary inner contradictions of the activity system: (Lim \& Hang, 2003)

The thin double faced arrows represent inner contradictions of the activity system. In addition, Boitsharelo (2007, p. 103) states, “... activity systems are always adapting towards resolving these contradictions and becoming more stable". Contrasting the external and internal of the activity system, he further describes that "... contradictions are usually internal; they may also be external, when the values, beliefs or activities of different but separate activities that influence the component of one activity system are known as nested activities". As a result, the external contradictions would be resolved by adjusting the nested activities.

Figure 08 below shows the integration of various activities and these activities are interacted with each other in an activity system. The interaction of the various activities within the activity system is called nested activities.



Figure 08: Nested natures of activity theory dynamics: source (Jonassen \& Murphy, 1999, p. 67) 
The figure shows categories of the nested activity system (the interacted and integrated activities in an activity system).

\section{Conclusions and Recommendations}

This paper focused on review the effectiveness and advantages of AT in research field, according to the findings of content analysis of historical cultural Activity Theory, the paper articulated the history and basic component of the AT. In addition, the paper the described importance of AT in different field in qualitative research and the paper will be helped to deeply understand applications of AT for the future studies in qualitative discipline.

\section{References}

[1] Bandara, B.M.S. (2010). School-based Teacher Development Programs in Sri Lanka, Deakin University, Melbourne, $\mathrm{PhD}$

[2] Boitshwarelo, B. (2007). Exploring Online Communities of Practice for Biology Teachers in Botswana. Deakin University. Melbourne.PhD

[3] Clark, J. C. (2006). The role of practical activities in primary school Science. Deakin University. Melbourne.PhD

[4] Davydov, V. V. (1999). The content and unsolved of activity theory.New York, Cambridge University Press

[5] Dennis, C., Frezzo, J. T., Behrens, R. J. \& Mislevy (2009). Activity and Assessment Theory in the Design and Understanding of the Packet Tracer Ecosystem. International Journal of Learning and Media, 1-22.http:/ijlm.net/knowinganddoing/10.1162/ijlm.2009.0015

[6] EngestrÖm, Y. \& Miettinen, R. (1999). Activity theory: A well-kept secret.New York, Cambridge University Press

[7] EngestrÖm, Y. (2001). Expansive learning at work: Toward an activity-theoretical conceptualization. Journal of Education and work, 14, 133-156

[8] EngestrÖm, Y. \& Sannino, A. (2010). Studies of expansive learning: Fundations and future challenges. Educational Research Review, Vol. 5, 1-24

[9] Jonassen, D. H. \& Murphy, L. R. (1999). Activity Theory as a Framework for Designing Constructivist Learning Envioronments. ETR\&D, Vol. 47, No. 1, 1999, 61-79

[10] Kutti, K. (1996). Activity Theory as a potential framework for human-computer interaction. IN NARDI, B. (Ed.) Context and Consciousness, Chapter 2.

[11] Lim, C. P. \& Hang, D. (2003). An activity theory approach to research of ICT integration in Sigapore schools. Computers \& Education, 41, 49-63

[12] Murphy, E. \& Rodriguez-Manzanares (2008). Using activity theory and its principle of contradictions to guide research in educational technology. Australian Journal of Educational Technoligy, 24, 442-457.http://www.ascilite.org.au/ajet/ajet24/murphy.html

[13] Murphy, E. \& Rodriguez-Manzanares (2008). Using activity theory and its principle of contradictions to guide research in educational technology. Australian Journal of Educational Technoligy, 24, 442-457.http://www.ascilite.org.au/ajet/ajet24/murphy.html

[14] Nardi, B. (Ed.) (1996a). Context and consciousness: Activity theory and human-coputer interaction, Cambridge, MA: MIT press.

[15] Nardi, B., A (1996b). Studying Context: A Comparison of Activity Theory, Situated Action Models, and Distributed Cognition.Cambridge, MIT press.

[16] Riverin, S. (2006). Effects of Online Professional Development on the Integration of Technology in Schools. Deakin University. Melbourne.PhD.

[17] Rothe, P. J. (2000). Understanding Qualitative Research.Albera, Canada Council for the Arts.

[18] Ryder, M. (2008). What is Activity Theory? 
http://carbon.cudenver.edu. mryder/itc_data/act_dff.html

[19] University of Tasmania (2008). Activity Theory. University of Tasmania.

Tasmania.http://ww.educ.utas.edu.au/users/ilwebb/Research/activity_theory.htm

[20] Waite, T. (2005). Activity Theory, Bloomington http://www.slis.indiana.edu/faculty/yrogers/act_theory2/

[21] Williams, J., Davis, P. \& Black, L. (2007). Sociocultural and Cultural-Historical Activity Theory: perspectives on subjectivities and learning in schools and other educational contexts. International Journal of Education research, Volume. 46, 17.http://www.sciencedirect.com/science?_ob=ArticleURL\&_udi=B6V

[22] Weber, R.P. (1990). Basic content analysis, second edition, qualitative application in the Social Sciences.London, SAGE Publications

*Corresponding author.

E-mail address: bandarabms@ gmail.com 